\title{
MAX WEBER Y LA CRISIS DEL SISTEMA DE VALORES LIBERAL
}

\author{
Wolfgang J. Mommsen \\ (Universidad de Colonia)
}

En el transcurso de una polémica con Heidegger, Karl Jaspers habl6 una vez de los grandes problemas de trascendencia mundial de Max Weber que, en la medida en que reciben solución parcial por la investigación concreta de tipo crítico, se transforman en problemas cada vez mayores e irresolubles. ${ }^{1}$ Lo que Jaspers dijo aquí sobre la obra filosófica y sociológica de Weber, a saber, que en el proceso de investigación concreta alcanza los límites del conocimiento, y que con la solución empírica parcial de los problemas existentes plantea nuevos problemas incomparablemente más difíciles, es algo que también puede decirse del pensamiento político de Max Weber. Sus preguntas incisivas alcanzaban constantemente los límites de las posiciones políticas que él consideraba correctas y ponfan al descubierto, en la situación marginal, el conflicto irresoluble entre los ideales alternativos de valotes. Vamos a estudiar con más detalle este fenómeno, en el campo específico de su pensamiento político; en concreto: su actitud de principio frente a la democracia liberal.

1. Karl Jaspers, Notizen zu Martin Heidegger, publ. por E. Sauer, Basel, 1977, p. 215. 
Desde el punto de vista político Max Weber seguía la tradición del nacional-liberalismo alemán de la época posterior a Bismarck. Sin embargo, ya en una época muy temprana comenzó a formar parte del ala izquierda del liberalismo y a interesarse por aquellos filósofos alemanes que antes de principios de siglo exigieton, consecuentemente, la parlatnentarización del Imperio alemán. Sin embargo, su defensa de una liberalización de la sociedad alemana iba unida a un nacionalismo apasionado que hacia 1880 se asociaba al teconocimiento de una decidida política alemana a nivel internacional. ${ }^{2}$ Dentro del ámbito de la política alemana de su época cabe calificar a Max Weber como representante de aquel imperialismo cultural que se puso de moda desde finales de los años noventa en los círculos intelectuales alemanes y, especialmente entre los catedráticos. Es difícil contestar a la pregunta acerca de hasta qué punto eran auténticas sus convicciones liberales o si sólo constituían un medio para reforzar la unidad del Estado nacional de poder. Sin embargo, es indudable que para él personalmente el fortalecimiento del liberalistno alemán sólo parecía imaginable en unión con una fuerte política imperialista nacional. Algunos autores más jóvenes como por ejemplo Jürgen Kocka, David Beetham o Anthony Giddens objetaton frente a semejante interpretación que Max Weber, aunque habiendo hecho considerables concesiones en este punto al espíritu imperante en la época era, en el fondo, un liberal convencido y que, frente a ello, su opinión nacionalista pasaba a un segundo plano. En nuestra

2. Cf. Wolfgang J. Mommsen, Mox Weber und die deutscbe Politik, 1890-1920, Tübingen $1974^{2}$, p. 13 y ss.

3. Jürgen Kocka, Kontroversen über Max Weber, en NPL, año XXI/1976, p. 282 y ss., especialmente p. 295 y ss. Delimitando las interpretaciones más antiguas del autor, Kocka pone de relieve el peso de «los elementos racionales y escjatecedores» en el pensamiento de Weber como elementos ampliamente doninantes y llega a la conclusión siguiente: «Si tomamos en serio la orientación weberiana sobre la base de esos valores Meta nos está prohibido suponer que su defensa de la opinión pública y de Ia emancipación burguesa, del parlamentarismo y de la democratizací́n sólo haya sido un medio para alcanzar el objetivo de los éxitos nacionales y de estado de poder... Similarmente, Anthony Giddens, Politics and Sociology in the Tbought of Max Weber, 
opinión las propias manifestaciones de Max Weber acerca del problema de Ia telación entre los ideales liberales y nacionales no permiten fácilmente esta clase de interpretación, sino que en este punto se manifiesta un con. flicto aporético en el propio pensamiento de Weber; conflicto que ha de tomarse en serio y que ha de estudiarse más a fondo. Aquí se nos descu. bre una de esas zonas marginales de su pensamiento en la que saltan a la vista de forma exagerada los conflictos entre posiciones alternativas de valores y en la que, a la vez, se perfilan claramente los problemas planteados por su teoría política.

En diversas ocasiones Max Weber manifestó expresamente que en su propia escala de valores prevalecía sin duda alguna la idea nacional frente a cuestiones de un orden constitucional liberal: «Los argumentos aducidos no tienen efecto sobre aquél para el cual las tareas históricas de la nación alemana no predominan por principio por encima de todas las cuestiones de su forma de Estado o sobre aquel que por principio ve desde otro ángulo esas tareas.» ${ }^{4}$ En otro pasaje hizo declaraciones mucho más taj̧an. tes en este contexto, a saber: "Para el signatario, la "democracia" nunca ha sido un fin en sí mismo. La posibilidad de una política nacional objetiva de una Alemania fuerte, unificada de cara al exterior, es la que le ha interesado y sigue interesando exclusivamente.» ${ }^{5}$ En consecuencia, no están indicados los compromisos fáciles. Hemos de partir más bien del hecho de que Weber ha sido tanto un nacionalista como también un liberal, y eso aunque ambas posiciones no sean perfectamente compatibles. Aquí nos encontramos más bien con una dicotomía dentro de su pensamiento polí. tico que no puede resolverse por la vía del compromiso, sino que más bien sólo puede resolverse dentro del marco de una interpretación sistemática.

El conflicto que se nos presenta aquí entre dos sistemas diferentes de valores nos parece sintomático de un rasgo fundamental del pensamiento político de Max Weber. El siempre llevó a los límites de lo posible, en un momento dado, la racionalización de determinadas posiciones a la

London 1972, p. 55 y ss., y David Beetham, Max Weber and the Theory of Modern Politics, London 1974, p. 113 y ss. y passim. Cf. también la interpretación de Gerhard Hufnagel, que ha elegido al ecríticon Weber como foco de su relación y que argumenta que el "crítico que desea luchar en contra de la corriente del tiempo "debe" sumer. girse totalmente en él». Crítica como profesión. Der kritiscbe Gebalt im Werk Max Webers, Frankfurt 1971, p. 102 y ss.

4. Gesammelte politische Schriften, Tübingen $1971^{3}$, p. 306.

5. Das Preußische Wahirecht, en Europäische Staats- und Wirtschaftszeitung, núm. 16, 1917. (Este texto, desconocido hasta ahora, no está incluido en la obra política completa.) 
luz de determinados ideales finales, como en este caso, por un lado, el ideal de un Estado nacional alemán fuerte y, por otro, el ideal de un orden social liberal. De esta forma puso agudamente en evidencia aquellos conflictos de valores fundamentales y antinómicos que normalmente quedan cubiertos por compromisos cotidianos fáciles. ${ }^{6}$ Esto es especialmente cierto en la doctrina de los valores liberales clásicos. En el propio pensamiento político de Weber, con su exagetación personal y extrema de las posiciones alternativas, se manifiestan a título representativo las diferencias y contradicciones dentro del sistema clásico y liberal de valores, cuando éste se ve confrontado con las condiciones de una sociedad industrial avanzada. En las dicotomías y antinomias en las que desemboca fnalmente su teoría política se refleja a la vez la crisis del liberalismo en una época de trans. formación de la sociedad burguesa en sociedad de masas. ${ }^{7}$ A continuación vamos a tratar de esclarecer, sobre la base de una serie de ámbitos objetivos, las tensiones y aporías que se presentan en la filosofía de los valores políticos de Max Weber en la medida en que los ideales de valores en juego han alcanzado la zona límite de su validez.

En primer lugar, estudiemos con más detalle el problema de por qué Weber pudo ser a la vez un liberal decidido y un nacionalista rígido que consideraba absolutamente necesatia una política internacional fuerte para el Imperio alemán, que en caso necesario no retrocediera ante una guerra. A la luz actual parece quedar claro que ambos ideales se contradecian, dado que el principio de la «autodeterminación democtática» es apenas compatible con una política internacional que persigue el establecimiento

6. Aqui coincidimos con Lepsius, quien parte de la base de las apatentes incompatibilidades en la posición política de Weber y manifiesta que ellas están relacionadas con la peculiaridad de su método sociológico. Dice: «Su investigación social comparativa de los distintos sistemas de dominio le llevó a comprender que no existen órdenes ideales y que, en consecuencia, sean susceptibles de institucionalizarse a largo plazo para los intereses cambiantes y que tampoco existe una jerarquía deducible de los últimos objetivos y valores...» El debate sobre la saciología de Weber sucumbe "con demasiada facilidad a la tentación de aislar su reconocimiento de los valores del contexto de su doctrina comparativa de las instituciones y de descuidar las antinomias entre tacionalidad formal y material, entre racionalidad de valores $y$ de objetivos, que constantemente realzó». Dice que Weber estaba realmente interesado en "dramatizar estas antinomias» (Max Weber in München, en Zeitschrift für Soziologie, año 6, 1977, p. 114). A continuación intentaremos poner de relieve precisamente esas antinomias en el ámbito político. Sin embatgo, nos diferenciamos de Lepsius en el sentido de que para nosotros la estructura antinómica de su pensamiento llega a penetrar hasta en su propio mundo, su propia vida, e.d., que no sólo tiene condicionantes metodológicos.

7. Cf. también el intento de interpretación del autor "A Libetal in Despait», en: el mismo autor, The Age of Bureaucracy. Perspectives on the Political Sociology of Max Weber, Oxford 1974 , p. 95 y ss. 
de una hegemonía del Imperio alemán en el continente europeo frente a las naciones más pequeñas. Hay buenas razones para suponer que Max Weber defendio un imperialismo alemán fuerte, en primer lugar, por razones tácticas, es decir, que en la inauguración de un imperialismo alemán él veía un medio para alcanzar una liberalización substancial de la sociedad alemana. Weber propagó la idea liberal en cierto modo para derrotar a los conservadores con sus propias armas. Una política imperialista conse cuente condicionaba, a la vez, una opción a favor del Estado industrializado. Sin embargo, esto se oponía de forma indirecta a la supremacía de Los conservadores agrarios en el Estado y la sociedad. Una política internacional racional exigía a la vez la modernizacion de la sociedad alemana, por un lado, para poner a disposición los tecursos materiales necesarios y, por otro, para permitir la medida necesaria de unidad interna de la nación. En este sentido la idea imperialista puede considerarse como una especie de ideología de emancipación dirigida en contra del predominio de la aristocracia prusiana en la sociedad alemana y que favoreció una liberalización del sistema político. Además el liberalismo volvería a obtener, de esta forma, un contenido nuevo y positivo y, como base de un gran programa encaminado al fututo, iba a alcanzar un nuevo auge.

Pero prescindiendo de estos puntos de vista que son, principalmente, de tipo táctico y que permitieron a Weber propagar una política imperialista siendo liberal, Weber fue imperialista por convicción. Aunque, en última instancia, esto apenas fue compatible con los ideales liberales, no hay que perder de vista que no sólo defendió una política de este tipo por consideraciones tácticas. En su opinión el Imperio alemán tenía prácticamente la obligación, en una época de conflictos imperialistas, de poder, de actuar como potencia mundial aunque sólo fuera para asegurar a la cultura alemana un lugar en el globo terrestre para los siglos venideros. Aunque Weber fomentata de forma activa, en un determinado momento del año 1911, una política de avenencia internacional, obviamente no retrocedió ante la idea de una gran guerra europea en la medida en que ésta demostrara sez inevitable en el transcurso de una fuerte política internacional alemana. Sin embargo, las circunstancias concretas bajo las cuales estalló finalmente la Primera Guerra Mundial le preocupaban profundamente. Aun asf́, no vaciló en justificar apasionadamente, sobre una base histórico-universal, los esfuerzos alemanes por prepararse para la guerra, a saber: «Teníamos que ser un Estado imperialista y para participar en la decisión relativa al futuro de la Tierra teníamos que correr el riesgo de esta guerra.» ${ }^{8}$ A la vista de la documentación existente es irrefutable la conclu-

8. Gesammelte politische Schriften, p. 176. 
sión de que una política imperialista activa de Alemania fue para Weber más que una mera estrategia hábil para aportar una nueva vitalidad al liberalismo alemán. Por otro lado su apasionada defensa de las reformas libetales internas como contrapartida necesaria a una política internacional fuerte, no fue de forma alguna un mero medio táctico para acrecentar el poder del Estado nacional alenán, aunque en muchas ocasiones se expresara de una forma que permitía llegar a esta conclusión. De hecho no se puede contestar inequívocamente a la pregunta sobre cuál de las dos jerarquías de valotes prevalecía en él, si la nacional o la liberal. Hemos de partir más bien de la base de que aquí en su pensamiento se perfila una dicotomía de principio que no puede eliminarse mediante unas simples interpretaciones.

De Weber se puede decir, en general, que despreciaba directamente los compromisos fáciles o las soluciones intermedias. Por mucho que reconociera, en principio, las soluciones pragmáticas en la política, no les concedía validez para los conflictos básicos de valores. En repetidas ocasiones puso de relieve que el destino inevitable del hombre moderno era equilibrar en su propio corazón, simultáneamente, las diferentes ideas y valores conflictivos. En nuestra opinión esto es especialmente cierto de su actitud política en Ia situación de 1914 que fue, a la vez, la de un liberal convencido y la de un macionalista alemán.

Es posible, sin embargo, reducir a una premisa conjunta de tipo fundamental estas dos posiciones, aparentemente difíciles de conciliar. Weber partía de la base de que en una sociedad amenazada en sus elementos principales por los procesos universales de la burocratización y racionalización de todos sus campos vitales exa necesario alcanzar un máximo de dinamismo en todos los planos de la vida social o de fomentat este dinamismo por todos los medios a disposición. En cierta forma Weber quería ver conservado lo más ilimitadamente posible, incluso bajo Ias condiciones de una sociedad industrial de masas de la época, el principio clásico de la competencia, es decir, la lucha en defensa de intereses, ora ideales ora materiales, por parte de distintos grupos e individuos de la sociedad dentro de un marco legal más o menos preestablecido. A ello correspondía su exigencia de una liberalización del sistema constitucional en el interior junto con una liberalización sinultánea de la actividad espontánea de los grupos y asociaciones dentro del sistema social; en una estructura, dentro de lo posible, pluralista de la sociedad, con un máximo de margen para los partidos políticos, donde los grupos y las comunidades de intereses puedan luchar por sus respectivos intereses parciales, Weber vefa, en consecuencia, una condición esencial para la conservación del orden liberal. Esta opinión tuvo su concepto análogo en el ámbito de las relaciones in- 
ternacionales. Por consiguiente, en principio Weber estaba a favor de un sistema internacional en el cual una pluralidad de Estados nacionales fuer* tes estuvieran en constante rivalidad. El rearme militar recíproco de los grandes Estados le pareció un efecto secundario lamentable peto inevitable de esta situación de por sí loable. Cuando después de estallar la Primera Guerra Mundial él comenzó a ver claramente que había terminado la época del Estado nacional autónomo y que, por el contrario, el lugar de una multiplicidad de Estados nacionales soberanos de distinto tango iba a ser ocupado por una mayoría de poderes hegemónicos, desea el establecimiento de una hegemonía alemana en Europa sobre todo para asegurar a los Estados nacionales del ámbito cultural centroeuropeo su propio lugar seguro dentro del sistema futuro de potencias mundiales en evolución. La pluralidad de las estructuras imperialistas y la conservación de un sistema de poder en el cual los distintos sistemas políticos y sociales se encontraban en una rivalidad constante pareció, en consecuencia, ser también una condición previa para la conservación de un máximo de pluralismo y dina. mismo dentro de la sociedad europea e incluso dentro de la sociedad mundial.

En este sentido encontramos aquí una conexión entre la defensa que Weber hace a favor de un imperialismo alemán, aunque comparativamen. te moderado, y sus ideales liberales. Esta conexión parece suprimir parcial mente la dicotomía antes citada entre ambas posiciones. La competencia de las potencias en el sistema internacional y las tensiones entre los distintos órdenes y estructuras sociales no sólo suponían una amenaza para la paz, sino que también tenían su aspecto positivo, aunque Weber lamentaba personalmente el que, sobre todo, los Estados europeos se vieran obligados a invertir una parte importante de su producto social en arma. mento relativamente improductivo.

Lo que se puede observar en el campo de las opiniones políticas cotidianas de Weber, también puede aducirse del modelo de constitución por él defendido, modelo que sirve asimismo de base para sus propuestas con. cretas sobre la reforma de la constitución alemana y para sus declaracio. nes teóricas sobre la esencia de la democracia y del orden liberal. Max Weber estaba convencido de que bajo las condiciones sociales que se habían desartollado en las sociedades industrializadas avanzadas de Occidente los ideales liberales clásicos habían perdido ampliamente su fuerza informativa concreta, en todo caso al menos su carácter inequívoco. Para él los derechos fundamentales liberales se habían transformado en algo natural o en fótmulas vacías que como tales no ofrecían ninguna orientación con* creta, a pesar de que no se podía prescindir de ellos, como tampoco se 
podia prescindir del pan de cada dí. ${ }^{9}$ De acuerdo con ello, según Weber, una renovación del liberalismo no podía remontarse sencillamente a las doc. trinas liberales clásicas, sino que debía volver a interpretar dichas doctrinas en relación con las circunstancias sociales concretas en las sociedades industrializadas del capitalismo tardío. Muchos elementos de la doctrina liberal ortodoxa, como por ejemplo el postulado de la autodeterminación del individuo, le parecían haber perdido casi toda su importancia bajo las condiciones existentes en una sociedad industrializada desartollada. ¿Acaso el principio de la autodeterminación debía extenderse por ejemplo al lugar de trabajo del individuo en la industria moderna? Obviamente no.

Con la modificación de las condiciones sociales como consecuencia del establecimiento del alto capitalismo se perfilaron asimismo modifica. ciones fundamentales en el catácter de los procesos de toma de decísión $y$ en las clases de formación de voluntad dentro de los sistemas liberales, hecho que Weber reconocío claramente. Con el desartollo de la democracia plebiscitaria, unido al establecimiento de las modernas y burocráticas organizaciones de partidos, cambiaron fundamentalmente las condiciones bajo las cuales el individuo podía ejercer una influencia activa sobre los acontecimientos políticos y con ello cambiaron las condiciones básicas de una política democrática en sí. En consecuencia, la concepción de Max Weber de la democracia parlamentaria tiene poco en común con las crea" ciones tradicionales y fundamentales de dominio democrático que desde Rousseau habían formado parte de la herencia de Occidente. No es fácil reconstruir de forma precisa la posición que tenderíamos a llamar «liberal tardía» de Max Weber. No puede haber lugar a dudas de que él, de acuerdo con la tradición liberal, partió de la base de que toda sociedad libre debía estar construida en principio de tal forma que cada uno de sus ciudadanos tuviera un máximo de autodeterminación y, en consecuencia, también participación en todas las decisiones políticas. Naturalmente Weber consideró que ésta era una exigencia que, en las condiciones del momento, había perdido casi todo su contenido concreto. Él consideró que era casi ingenuo creer que bajo condiciones de la época el pueblo en su totalidad iba a estar en situación de decidir acerca de su propio destino político en unas elecciones libres. Lo único que en su opinión caracteriza a la democracia constitucional frente a otras formas de gobierno es el hecho de que ésta practica un sistema de elección formal y libre de los líderes, es decir, que el pueblo mismo decide cuáles han de ser sus «dueños y señores», mientras que en otros sistemas la selección de los líderes políticos la rea-

9. Un reconocimiento parcial de la posición dicotómica que se vislumbra aquí se encuentra ya en Giddens, p. 58, casi en contra de la voluntad de éste. 
Liza siempre una élite más o menos cerrada. En una ocasión Max Weber expresó muy tajantemente frente a Robert Michels lo siguiente: «... iAy cuánta tesignación tendrá que soportar usted aún! Los conceptos como "voluntad del pueblo", "verdadera voluntad del pueblo", etc., han dejado de existix para mí desde hace tiempo. Son ficciones, ${ }^{10}$ Dicho en otras palabras, la fundamentación jurídico-natural clásica del sisterna democrático significaba poco para Weber. En opinión de Weber la democtacia constitucional se diferencia de las otras formas de gobierno sólo por el hecho de que el pueblo está en situación de elegir sus líderes de forma libre y formal, líderes que parecen ser más capaces que otros para defender los intereses y objetivos propios del pueblo. Sin embargo, en su opinión y desde la perspectiva del individuo de la gran masa esto cambia poco o nada en relación con el carácter de dominio incluso de la democracia. Él consideraba «utópica toda idea de eliminar el dominio del hombre sobre el hombre por medio de cualquier sistema social, por muy socialista que fuera, por medio de una democracia, por muy desarrolladas que fueran sus formas»."

De hecho eI concepto de Weber de la democracia pariamentaria tiene poco en común con aquellos principios básicos, jurídico-naturales y fundamentalistas que nosotros asociamos en general a la democracia patlamentaria. Aquí se pueden reconocer más bien dos posiciones en tensión recín proca constante que Max Weber, con implacabilidad intelectual, Ilevó respectivamente hasta los límites de lo imaginable. Por un lado el principio de la autodeterminación del individuo que en última instancia se deduce del valor fundamental de la dignidad del ser humano, que como persona jamás debería estar sometido a determinación ajena, sino que debería actuar sobre la base de una propia iniciativa libre. Por otra parte es el reconocimiento de que todas las condiciones sociales son, en última instancia, condiciones de dominio y de que incluso las distintas variantes de los sistemas democráticos no pueden suprimir en principio el dominio, es decir, la determinación ajena de individuos, sino que en el mejor de los casos pueden crear las condiciones óptimas para que el margen de libertad pata la propia iniciativa del individuo esté sometido a un mínimo de limitaciones. En cierta forma es la tensión entre estos dos principios fundamentales, a saber, el principio de la libre autodeterminación del individuo como condición formal para la posibilidad de la libertad en sí y el princi. pio del dominio como condición material para crear y conservar un orden

10. Carta a Robert Michels del 4 de agosto de 1908, Fondazione Luigi Einaudi, Turin. Citado en Mommsen, Max Weber, p. 421.

11. Ibidem... Citado en Mommsen, Max Weber, p. 421. 
social de esta índole y que es el único que permite un máximo de libertad, la que sirve de marco para las consideraciones de Max Weber sobre la forma óptima de un orden democrático.

Weber consideraba que era un postulado natural y a la vez bastante ingenuo el que el dominio democrático siempre tuviera que estar basado en la aprobación de los dominados. Si es que la democratización tiene un sentido preciso en condiciones modernas «entonces tan sólo será el de una "minimización del poder de dominio de los funcionarios profesionales" a favor de un dominio en lo posible "directo" del "Demos", lo que quiere decir en la práctica de sus respectivos jefes de partidos». ${ }^{12}$ En consecuencia Weber quería que se reformulara la exigencia liberal clásica de la autodeterminación del pueblo de la forma siguiente, es decir, el derecho del pueblo de elegirse su propio líder formal y libremente unido a las disposiciones institucionales que permiten la dimisión o el intercambio de los líderes, una vez que hayan perdido la confianza de las masas. Considerada desde un punto de vista realista, la democracia según Weber puede set en el mejor de los casos el dominio por parte de líderes elegidos libremente y que en principio proceden luego de acuerdo con su propio juicio. Pero no podrá ser nunca una substitución del dominio por un sistema de autodeterminación general de abajo hacia arriba.

Frente a la teoría fundamentalista clásica de la democracia, el «derecho de la libre elección de líderes» es insufiente como tal. Weber estaba convencido, sin embargo, de que esto «no era tan poca cosa», ${ }^{13}$ sino que incluso era la substancia del dominio democrático en sí. En vez de fundamentar formalmente el dominio democrático en el consenso del pueblo que elige a sus mandatarios para dirigir el aparato del Estado, Weber defiende el principio de la lucha competitiva de aquelios que son capaces de ser líderes y que tienen la «vocación» interna de fijar objetivos a las grandes masas. En este contexto, las técnicas plebiscitarias de la demagogia y de la unión emocional entre las masas y el líder constituyen métodos legítimos. En cierta forma se invirtió el principio clásico de la legitimación del dominio por medio de un proceso de formación de voluntad desde abajo hacia arriba. Son los líderes los que gracias a su capacidad personal y en úlitiona instancia gracias a la utilización de su carisma personal los que haciendo uso de aptitudes demaǵgicas en el sentido positivo de la palabra, obtienen seguidores en la gran masa. Las masas juegan en

\section{Ibidem.}

13. A Robert Michels el 6 de noviembre de 1906, Fondazione Luigi Einaudi, Turín: «La democratización política es lo único que puede alcanzarse tal vez en un futuro previsible - (y) no es tan poca cosa...” 
este contexto un papel meramente pasivo. Weber consideraba que era prácticamente imprescindible esta forma plebiscitaria personal de fundamentar la autoridad política y, con ello, el dominio sobre todo en los Estados modernos de masas. Sólo quería reconocer como realistas las formas directas de formación de la voluntad política desde abajo hacia arriba en espacios reducidos, como por ejemplo, en los cantones suizos.

Aquí nos encontramos con otra posición dicotómica en el concepto de democracia de Weber. Por un lado ha de asegurarse el principio de la autodeterminación del individuo por medio de la elección formal y libre, es decir, sin limitación de contenido, del líder respectivo, así como por medio de un apoyo adicional de este acto electivo por parte de las instituciones parlamentarias. Por otro lado, sin embargo, Weber pone de relieve enfáticamente que en principio el liderazgo democrático es una forma de autoridad con fundamento carismático, que sólo deriva formalmente de la voluntad del «dominado» y no substancialmente. Esta voluntad del «dominado" sostiene el liderazgo democrático. Según. Weber los líderes gobiernan exclusivamente sobre la base de su propia responsabilidad personal. En cambio no se les puede considerat de forma alguna, ni substancial, ni materialmente, como mandatarios de sus electores. Más aún, su autoridad de líderes se fundamenta en gran medida y, quizás exclusivamente, en la fe emocional de los electores y de sus seguidores, en sus capacidades formales de liderazgo, mientras que las cuestiones materiales pasan totalmente a un segundo plano e influyen en las relaciones entre líderes y seguidores a lo sumo en casos marginales. Este áltimo concepto Weber lo ha levado con profundo rigor hasta el límite extremo de lo imaginable, porque esta. ba convencido de que todo orden democrático efectivo $\mathrm{y}$, en sentido más amplio, toda sociedad libre dependía de la existencia de grandes líderes democráticos que actuaran sobre la base de su propia responsabilidad personal. Finalmente llegó a definir la democracia parlamentaria en todas sus formas como una variante antiautoritaria del dominio carismático. «La "democracia plebiscitaria", el tipo más importante de democracia de líderes, es, de acuerdo con su sentido genuino, una clase de dominio catismá" tico que se esconde bajo la forma de una legitinidad derivada de la vo luntad del dominado y que sólo puede seguir existiendo gracias a esa voluntad del dominado. El líder (demagogo) domina de hecho en virtud de la lealtad y de la confianza que tienen sus seguidores frente a su per. sona.s ${ }^{34}$

Aquí en este punto vemos clazamente una contradicción, en aparien-

14. Wirtschoft und Gesellscbaft, publ. por Johannes Winckelmann, Tübingen 1976, tomo I, p. 176. 
cias irresoluble, entre la exigencia de un liderazgo democrático fuerte y la idea de la autodeterminación del ciudadano que deberá quedar asegurada a través del sistema parlamentario de representación. La defensa consecuente de este último principio, a saber, la imposición ilimitada de la vo luntad de la gran masa frente al respectivo gobienno del Estado, unida a la exigencia de una "minimización del dominio del hombre sobre el hombre» lo más amplia posible lleva, en opinión de Max Weber, en el mejot de los casos a la creación de una "democracia sin líderes», caracterizada por el dominio de "políticos profesionales» sin profesión, sin las propiedades carismáticas intetnas que les transforman en luderes..$^{15}$ En este tipo de sistemas toda política se transforma en mera rutina. Un acto político creativo tiene pocas o ninguna posibilidades. Bajo puntos de vista histórico-univetsales Weber consideraba que precisamente esta última forma de dominio democrático constituía un peligro grave para la continuación de un orden libre en el mundo occidental. En cambio, concedía poca importancia al cambio de un dominio de líderes con legitimación plebiscitaria dentro del marco de una «democracia de líderes», aunque subrayó que «era propio de las democtacias de líderes el carácter emocional natural de la entrega y de la confianza en el líder» y que de ello resultaba la tendencia de «seguir como líder al extraordinario, al más prometedor, al que más alicientes utilizam. ${ }^{\text {to }}$

Weber partió de la base de que en la situación histórica de una so ciedad industrializada y desarrollada de masas se planteaba equivocadamente el problema clásico de cómo podía el pueblo controlar eficazmente al gobietno dentro de un sistema democrático y, sobre todo, de cómo podían bacerse depender las decisiones del gobierno de la voluntad del puebio. El auge del capitalismo industrial, de la potencia más revolucionaria en sí de la historia, como dijo Weber en alguxas ocasiones, estaba estrechamente unido en su opinión al progreso incontenible de la burocratización y de la racionalización. Estas formas de organización y de comportamiento sociales favorecidas más y más en el transcurso del desarrollo del capitalismo servían, sin embargo, para socavar los valores e ideales liberales tradicionales $y$, fnalmente, incluso la libertad del individuo de forma idéntica.

Con cierto pesimismo constató que las sociedades libres de Occidente estaban expuestas a un proceso de rutinización y de racionalización a todos los niveles de la vida social que llevaba con paso lento pero certero a la patalización de todas las iniciativas individuales. Al frnal de ese proceso ya no se iba a poder hablar de libertad en ningún sentido. La posibilidad

15. Cf. Gesammelte politische Schriften, p. 544.

16. Wirtscbatt und Gesellschatt, tomo I, p. 157. 
de que las sociedades libres de Occidente se pudieran sumergir en una segunda Antiguiedad tardía le parecía real a Weber. El dijo en algunas ocasiones que por ello la pregunta decisiva tenía que ser la siguiente: "¿Cómo ha de ser posible salvar cualquier resto de una libertad de movimiento "individualista" en algún sentido a la vista de la supremacía de la tendencia hacia la burocratización ?» ${ }^{17}$ Weber estaba convencido de que esta exigencia era especialmente válida para los ótdenes políticos de su presente. Weber consideraba que existía evidentemente el peligto de una degeneración de los sistemas modernos de estado social y democracia de masas en sociedades estáticas y que iba unido a un creciente retroceso de movilidad política y social, lo que equivalía en su opinión a una reducción progresiva de los márgenes de libertad aun existentes del industrialismo, y no importaba en este contexto la definición que se le diera a la libertad.

Weber observó con buenas razones que en las condiciones de la sociedad industrializada moderna no sólo los sistemas estatales autoritarios como el Imperio alemán tendían hacia una falta de liderazgo, sino que también lo hacían las democracias parlamentarias. El consideraba que frente a ello el llamamiento al carisma del gran político constituía el único medio efectivo para garantizar en las sociedades modernas un máxinoo de liderazgo político efectivo. En la combinación de dos tipos de dominio en sí alternativos, a saber, el dominio democrático basado en el consenso del pueblo sobetano y tendente a una falta de dominio y una vatiante específica de dominio carismático, basado exclusivamente en la autoridad personal del gran político carismático, esperaba Weber restablecer aquellas condiciones bajo las cuales pudiera mantenerse también en un futuro la «libertad», incluso bajo las circunstancias de la sociedad de masas del capitalismo tardío cargada de innumerables burocracias.

En condiciones modernas, sin embargo, incluso un liderazgo carismático no puede prescindir de los elementos esenciales de las formas burocráticas de dominio. El dominio plebiscitario personal de pocos grandes políticos se sirve de los aparatos de administración burocrática o de organizaciones de partidos burocráticos que están «entregados ciegamente» por cierto a los líderes respectivos. Ellas se ocupan de que sus decisiones, adoptadas en última instancia exclusivamente por responsabilidad personal y propia, se aprueben por el Estado y la sociedad y se realicen, a la vez, de forma eficaz. También aquí nos encontramos, por tanto, con una solución dicotómica. El dominio plebiscitario personal de los grandes políticos democráticos ha de servirse de medios burocráticos aunque ya por ello

17. Gesammelte politische Schriften, p. 333. 
corran el peligro de perder su carisma y de verlo reemplazado paulatinamente por la rutina. Max Weber ha estudiado detenidamente los distintos tipos de democracias modernas que intentaron funcionar con un aparato administrativo no constante o con un mero funcionariado electivo, como el antiguo sistema ameticano. ${ }^{18}$ Finalmente llegó a la conclusión de que ya no se les podía dar ninguna posibilidad de éxito bajo las circunstancias del momento. Tan sólo la combinación de liderazgo sobre una base carismática con una disciplina burocrática estricta parecía tenet posibilidades de éxito bajo circunstancias modernas. En 1919 expresó tajantemente esta opinión de la forma siguiente: «Tan sólo cabe elegir entre democracia de líder y "máquina" o "democracia sin líder", es decir, el do minio de los "políticos profesionales sin profesión" sin las capacidades carismáticas que les transforman en líderes.» ${ }^{19}$ Se puede decir que Max Weber veía la mejor posibilidad para asegurar una sociedad abierta con un máximo de libertad y un margen óptimo de autodeterminación individual de todos los individuos bajo las circunstancias sociales del sistema capitalista tardio no en la mezcla de principios de organización política alternativa, sino en su combinación dialéctica.

Weber llegó a conclusiones muy análogas en su análisis del subsistema económico. Max Weber ya se ocupó en una época temprana del problema de los oxígenes del capitalismo y especialmente de sus efectos sociales a largo plazo. Consideró que el capitalismo industrial moderno, que fue esencialmente una creación de la burguesía protestante y que en su fase inicial del capitalismo precoz había vencido a las sociedades más antiguas, tradicionales de tipo clasista y feudal antiguo, había ofrecido condiciones positivas únicas en la historia para que se impusieran ideas liberales en el Estado y la sociedad. Sin embargo, dudaba de que fuera válido asimismo para el capitalismo monopólico maduro.

En relación con sus análisis de la revolución rusa de 1905 en la que los liberales de Occidente habian visto frecuentemente una manifestación decisiva que también haría triunfar en Rusia el orden liberal, dijo en una ocasión lo siguiente: «Es totalmente ridículo adjudicar algún parentesco electivo con "democracia" o incluso con "libertad" en algún sentido de la palabra al capitalismo muy desarrollado de la actualidad, tal como se importa ahora en Rusia y como existe en América, es decir, a esa "inevitabilidad" de nuestro desarrollo económico, pues sólo cabe preguntar cómo son "posibles" estas cosas a largo plazo, es decir, la libertad personal, de-

18. Cf. al respecto el ensayo del autor, Max Weber. Gesellschaft, politik und Geschichte, Frankfurt 1974 , p. 88 y ss.

19. Cf. nota 14 . 
rechos humanos, etc., bajo su dominio." ${ }^{20}$ En consecuencia Max Weber estaba convencido de que el desarrollo económico como tal amenazaba con transformarse en una creciente limitación de libertad y que por lo tanto la lucha por imponer principios liberales en el capitalismo altamente desarrollado tenía que ser llevada uen contra de la corriente de los intereses materiales»."1

Weber estaba profundamente preocupado de que las estructuras capitalista-monopolistas transformaran en un modelo obsoleto el modelo clásico liberal de la sociedad y que a la vez iban a acelerar extraordinariamente la tendencia hacia aparatos buroctáticos cada vez más poderosos. Con ocasión de un debate sindical de la Asociación para Política Social, en el año 1905, defendió el punto de vista de que ya no podía partirse de la base de que los sindicatos siguieran siendo lo suficientemente fuertes a la vista de la creación de «empresas gigantes» como para imponerse frente a las grandes corporaciones y empresas y poder actuar con eficacia en favor de un salario justo para los trabajadores sin medidas adicionales de apoyo por parte del gobierno. Por otro lado rechazaba expresamente una mediatización de los sindicatos por una intervención directa del Estado o por un sistema de arbitraje establecido por el Estado. Quetía evitar a toda costa una reducción de la lucha competitiva entre los trabajadores y las asociaciones de empresarios. Sólo quetía mejorar indirectamente, por medio de métodos adecuados, las condiciones básicas de los trabajadores en posibles luchas obreras. ${ }^{22}$ En 1912 intentó por medio de la fundación de una asociación de políticos sociales activos dar un nuevo auge a la polí. tica social alemana tan paralizada en aquel entonces, a fin de dar más flexibilidad a las relaciones entre pattonos y trabajadores y de encauzar de esta forma la emancipación de los trabajadores dentro del sistema existente. ${ }^{23}$

Cada vez más observamos en los artículos de Weber sobre La ética protestante y el espiritu del capitalismo (Die protestantische Etbik und der Geist des Kapitalismus) su preocupación de que el capitalismo altamente desartollado, en caso de continuar ininterzumpidamente el desarrollo de aquel entonces, produjera una «nueva servidumbre del futuro» del modelo de la antigüedad tardía. Weber observó desapasionadamente que la mo derna sociedad industrializada capitalista, organizada meramente de acuer-

20. Referente a la situación de la democracia burguesa en Rusia, citado según el resumen en Gesammelte politische Scbriften, p. 6 y ss.

21. Ibidem..., p. 64 .

22. Ct. Mornmsen, Max Weber, p. 123 y ss.

23. Cf. Bernhard Schäfers, Ein Rundscbreiben Max Webers zur Sozialpolitik, en: Soziale Welt, año 18, 1967, p. 261 y ss., y Mommsen, Max Weber, p. 126 y ss. 
do con el principio de la racionalidad formal, amenazaba con conducir a una deshumanización del mundo del trabajo y que favorecía el desplazamiento de la personalidad de la vida social. Pronto reconoció, sin embatgo, que la alternativa ofrecida por Marx, es decir, la socialización de los medios de producción como panacea en contra de la subyugación especial. mente de la clase obrera, era un sucedáneo de solución, ya que ello sólo llevaría a intercambiar la élite que domina y dispone de los medios de producción por una nueva élite burocrática, sin modiffcar, en absoluto, la situación de la clase obrera como tal. Por lo demás, ello empeotatía aún más las cosas, dado que por un lado la lucha de clases continuaría en condiciones mucho menos favorables para la clase obrera. Esta clase obrera tendría que enfrentarse en ese caso a un único oponente, la burocracia monolítica, mientras que hasta entonces podía contar con el apoyo de la burocracia estatal en el caso de exigencias extremadas por parte del empresariado. En segundo lugar, y esto fue decisivo para el análisis que Weber hizo de la situación, se reforzaría enormemente la tendencia ya existente de por sí hacia la burocratización. Además el sistema industrial moderno no podía prescindir en absoluto de la iniciativa y actividad de empresarios individuales de tipo privado. ${ }^{24}$

Weber estaba convencido de que el capitalismo, que había entrado en su fase de madurez, ya no tequería esa fuerza motriz específicamente individualista a la que debía su origen, sino que obligaba a un determinado modo de vida y no importaba si los afectados lo querían o no. «EI puritano quiso ser profesional, nosotros lo bemos de ser.» ${ }^{25}$ El sistema capitalista evolucionado desarrolla, según Weber, un creciente poder mecánico que se transforma, en última instancia, en un «poler ineludible sobre el hombre, como nunca antes en la historia» y que obliga a una forma de vida que ya no concuerda con los ideales clásicos de la libertad y espontaneidad individuales. Esta espontaneidad creativa del individuo puede conservarse a lo sumo en la esfera privada.

Estos pronósticos sombríos, en parte incluso apocalípticos, los basaba Weber también a la vez en análisis muy precisos del modelo fundamental de una otganización capitalista de la economía y de la sociedad. En este contexto se basaba ampliamente en los análisis clásicos de Karl Marx. Según Max Weber el capitalismo moderno productivo se basa en el principio de la «racionalidad formal» de todas sus operaciones, e. d., el cálculo racional y general de todos sus procesos de trabajo con el objetivo de al-

24. Documentación y referencias a la literatura correspondiente en Mommsen, Max Weber. Gesellschaft, politik und Gescbichte, p. 156 y ss.

25. Gesammelte Aufsätze zur Religionssoziologie, Tutbingen 1920, tomo I, p. 203. 
canzar un máximo de rendimiento y eficiencia. No depende meramente de la voluntad de los individuos y grupos afectados, sean empresarios u obreros, de someterse o no a los principios férreos de la racionalidad formal. La competencia en el mercado obliga a ello. La racionalidad formal, al menos como idea reguladora, es un principio elemental del orden capitalista como tal. De hecho un capitalismo estructurado para maximizar su propia ley fundamental exige en primer lugar «la lucha constante de grupos autónomos en el mercado»; en segundo lugar, «la posibilidad de calcular racionalmente los precios y las condiciones de competencia ilimitada en el mercado»; en tercer lugar, «trabajo formal y libte», es decir, trabajo sobre la base de convenios colectivos libres en los que exista, en lo posible, una correlación directa entre productividad alcanzada y salarios, y, final. mente, cosa que se pone expresamente de relieve, la «expropiación de los trabajadores de los medios de producción». ${ }^{26}$ Esto quiere decir con otras palabras, que el sistema capitalista en su forma pura no sólo impone condiciones al individuo, condiciones sobre las que éste ya no puede influir, sino que evidentemente requiere los medios del dominio y de la opresión para su existencia continuada. Como es sabido, Weber ha calificado la relación laboral formal y libre entre trabajadores y empresarios en un sistema capitalista de forma de dominio equivalente a otras. En algunas ocasiones manifestó expresamente que un máximo de "racionalidad formal» de un sistema capitalista inevitablemente se pagaba con «irracionalidades matetiales», entre otras, con «la subyugación el trabajador bajo el dominio de los empresarios». "7 También aquí podemos observar que Weber, siguiendo en este sentido en parte a Marx, subrayaba tajantemente la tendencia inminente del capitalismo a enredar a los seres humanos en un sistema de dependencias indisolubles. ${ }^{28}$ Pero para Weber eta justamente una posibiiidad más para demostrar que el principio de la «racionalidad formal» de una organización capitalista de la sociedad se contradecía necesariamente

26. Wirtschatt und Gesellschatt, tomo I, p. 87. Ct. Mommsen, Max Weber. Gesellschatt, Politite und Gescbicbte, p. 173 y ss.

27. Wirtschaft und Gesellscbaft, tomo I, p. 44, p. 78. Alli se dice lo siguiente en una acentuación característica del carácter dicotómico del sístema capitalista bajo el punto de vista de su valoración desde la perspectiva de un liberalismo con cuño humanista: «El que el máximo de tacionalidad formal del cátculo del capital sea posible sólo sometiendo a los trabajadores bajo el dominio de los empresarios es otra irracionalidad material específica del orden econónico.»

28. El conocido problema planteado por Herbert Marcuse de la medida en que Weber pretendió alcanzar una justificación del capitalismo y racionalidad formal se basa en el fondo de esta dicotomía que el mismo Weber ya había realzado expresamente. Cf. los debates en el XV Congreso Alemán de Sociólogos de 1965, Max Weber und die Soziologie beute, publ, por Otto Stammler, Tübingen 1965, p. 161 y ss. 
con el principio de la «racionalidad material». Entre semejantes ptincipios de racionalidad material también podemos considerar los ideales liberales clásicos, especialmente el principio de la libre autodeterminación del individuo.

Esto significaba, en otras palabras, que el sistema capitalista en el transcurso de su desartollo tenía que entrat en conflicto, casi necesariamente, con el sistema clásico de los valores liberales. En este sentido el capitalismo, según Weber, es con razón una «estructura dura como el acero» que parecía limitar más y más el campo de la actuación individual espontánea, A pesar de esta comprobación desilusionadora Weber creía que no existía solución real para esta situación. Consideraba impracticable la solución propuesta a partir de Marx, de una revolución socialista que pudiera volver a liberar a la gran masa de su situación alienada. Por el contrario, una revolución socialista unida a la expropiación de los medios de producción por una nueva clase de funcionatios del Estado (la única forma de economía socialista a la que Max Weber estaba inclinado a dar una posibilidad de supervivencia) empeoraría con toda seguridad aún más los problemas fundamentales. Por un lado se fomentaría así decisivamente la tendencia universal hacia la burocratización en todas las esferas de la vida, incluso en la esfera económica, y, por otro, a través de la expropiación de los medios de producción no se eliminaría la lucha de clases en sí, como tampoco mejoraría notablemente la situación de los trabajadores. Por el contrario, tendrían muchas menos posibilidades de defender con éxito sus intereses específicos frente a la clase de las propietarios de los medios de producción que bajo condiciones de un capitalismo privado, en el que existía al menos la posibilidad de servirse de la clase de los propietarios de los medios de producción en contra de la clase política dominante, o viceversa. Todo lo contrario, Max Weber seguía viendo en un sistema económico dinámico y orientado hacia el mercado la mejor premisa para mantener en las sociedades modernas un máximo de dinamismo y con ello indirectamente también un máximo de libertad. De acuerdo con ello abogó por mantener, en lo posible, un sistema de economía de mercado, dado que consideraba absolutamente imprescindible sus efectos dinárnicos sobre la sociedad en general. No fue casualidad que aún en el año 1919, es decir, en la culminación de la revolución alemana rechazara estrictamente todas las formas de la llamada ueconomía mixta» y exigiera el regreso a un capitalismo competitivo puto de tipo clásico, manifestando que la sociedad alemana no podía prescindir de la fuerza dinámica de las figuras de empresarios como Thyssen o Stinnes si quería volver a recuperar su antigua posición en los mercados mundiales.

La manifiesta paradoja con la que Weber por un lado diagnosticó que 
Las tendencias inmanentes dentro del capitalismo perseguían un estancamiento y una rigidez de las relaciones sociales pero con la que por otro lado veía en el capitalismo, y, en especial en el principio de la competencia de mercado, un medio para alcanzar un máximo de dinamismo en el sisterna económico y, de forma secundaria, también en el sistema político, encuentra su solución parcial en el campo político. Weber adjudicaba al Estado la tarea de establecer las condiciones marco dentro de las cuales debía operar el subsistema económico. Partía de la base de que a pesar del hecho de que el Estado, por regla general, sólo era el instrumento de los grupos predominantes en un momento dado, podía tener un papel telativamente autónomo dentro del sistema social general. El Estado como institución con prerrogativas especiales en comparación con otras institu* ciones de la sociedad tenía el deber de intervenir, en la medida de lo necesario, en los procesos económicos y sociales. En cierta forma Max W/e ber puede ser considerado por to tanto como uno de los precursores del Estado intervencionista. La potencia del Estado debía garantizar en la esfera económica $y$, de forma secundaria también en la esfera social, las estructuras pluralistas que condicionan la posibilidad de la libertad en sí, en. tre las que se encuentra especialmente la conservación de un máximo de competitividad en el mercado y, en relación indirecta con ello, la conservación de un máximo de dinamismo. Weber no era optimista ni mucho menos. Sin embargo, estaba a favor de utilizar todos los medios disponibles para impedir el peligro universal de que las telaciones económicas y sociales existentes dentro de la sociedad se estancaran a un nivel alcarnzado y que así un sistema de metcado orientado a la competencia fuera reemplazado por un sistema de apropiaciones fijas de participaciones de mercado a plazo indefinido. Lo último le parecía el comienzo de una «segunda antigüedad tardias. Max Weber fue un defensor decidido de una política social progresiva que debía compensar en lo posible las desigualdades e injusticias existentes en el sistema social, aunque fuera a costa del principio de la organización formal y tacional del sistema capitalista. En virtud del hecho se trataba de alcanzar por medio de medidas estatales apropiadas un equilibrio adecuado a las circunstancias existentes, entre los principios de la "racionalidad formal», como la que exige el sistema capitalista de mercado para su funcionamiento óptimo, y los principios de la «racionalidad material», que se derivan en última instancia de los principios liberaies. Era naturalmente necesario hacerio de una forma tal, que no ser vieran reducidas las posibilidades de los distintos grupos políticos y sociales de la sociedad de defender libremente sus intereses ideales y materiales dentro de un sistema legal formal con estatutos correctos. Weber temía sobre todo una forma de organización social en la que los distintos 
grupos sociales se apropiaran rígidamente, de forma casi mecánica y a plazo indefinido de determinadas partes del producto nacional y que con ello se produjera una especie de silencio sepulcral artificial dentto de la sociedad. Era tarea de la política impedir por todos los medios una degeneración del sistema capitalista en una estructura social estancada en la que el producto nacional fuera distribuido de una vez y para siempre según reglas burocráticas entre los distintos grupos sociales.

De acuerdo con esta concepción Weber consideraba que un empresatiado independiente era un elemento imprescindible de todo orden social y económico dinámico. En especial bajo este punto de vista le preocupaba enormemente que en partes de la burguesía alemana se iba desarrollando en creciente medida una mentalidad de pensionista, que se diferenciaba radicalmente del espíritu empresarial capitalista de la primera época del capitalismo. Le preocupaba también el hecho de que el Estado social moderno pudiera entrañar grandes peligtos para una sociedad dinámica de corte liberal en la medida en que asegurase a la gran masa garantías sociales que pudieran socavar su voluntad de rendimiento: «En el benevolent feudalism ameticano, en las llamadas Woblfabrtseinricbtungen (instituciones sociales) alemanas, en las disposiciones industriales rusas, en todos los sitios está terminado el edificio de la nueva servidumbre. Sólo espera que el ritmo más lento del "progreso" económico deje tan "dóciles" a las masas como para inducirlas a entrar en él.» ${ }^{20}$ No obstante, a pesar de su rechazo decidido a una política social tendente al desarrollo de un sistema social que liberara totalmente al individuo de la responsabilidad de cuidar de su propia existencia, Weber no fue de forma alguna un liberal al estilo de Manchester, como ya se ha dicho. Más bien insistía en una política social y económica activa, aunque exclusivamente con el fin de restablecer el equilibrio social entre los distintos grupos de la sociedad, alterado por el desarrollo, por medio de tnedidas intervencionistas adecuadas. El modelo liberal y clásico de la sociedad y el modelo de un capitalismo competitivo puro, como to reconstruyó en Wirtscbaft und Gesellschaft (Economía y Sociedad) aproximándose, en principio mucho a Marx, servían en este contexto de medios de diagnóstico para calcular los correspondientes costes sociales que resultasen de determinadas medidas, en caso de apartarse éstas de la línea ideal de la racionalidad formal de un orden social libre, orientado a la competencia.

Una política de intervención constante en los ótdenes sociales y económicos, con el fin de mantener. las estructuras pluralistas existentes y de garantizar de esta forma un máximo de dinamismo dentro del sistema so-

29. Gesammelte politische Schriften, p. 63. 
cial, requería una autoridad fuerte y a la vez independiente. En contraposición a la doctrina clásica del liberalismo de Manchester Max Weber exigia en consecuencia un Estado fuerte, como condición de la posibilidad de libertad en el sentido propio de la palabra. También aquí se vuelve a combinar un postulado clásico del liberalismo, a saber, la liberación de la sociedad del Estado, con un principio contrario y dicotómico del Estado intervencionista. Weber se burlaba de la ideología liberal ortodoxa que había exigido una reserva máxima det Estado en cuestiones económicas y so ciales, diciendo que «no llegará a tanto la democracia». ${ }^{30}$ Reemplazó de forma consectente el ideal tradicional de una uminimización del dominio del hombre sobre el hombre» a favor de la «administración de cosas» por el ideal de un Estado poderoso, con control democrático, capaz de actuar resueltamente y que estuviera en situación de fjar objetivos a los grupos económicos y sociales. ${ }^{31}$

En este punto se cierra el círculo de nuestras reflexiones. Tan sólo los verdaderos políticos, capaces de fijar grandes objetivos a la sociedad pueden, en opinión de Weber, realizar semejante política social. Por el contrario, un dominio por «políticos profesionales sin profesión» es francamente peligroso, dado que se esfuerzan por afianzar las condiciones politicas y sociales existentes y se transforman así en cómplices, transigentes, de la burocracia. Tan sólo una democracia plebiscitaria dirigida a una pequeña élite de políticos calificados, que persigue dominio efectivo y un desarrollo máximo del poder hacia dentro y hacia fuera, y que está en contraposición a la udemocracia anticuada, negativa, que sólo exige libertad del Estadow, ${ }^{32}$ parecía capaz de resolver realmente estos problemas políticos. Era lógico, en consecuencia, que Weber abogara por el desarrollo de un nuevo tipo de democracia, a saber, la «democracia plebiscitaria

30. Gesammelte politiscbe Scbirtten, p. 269.

31. Cf. carta a Michels de 4 de agosto de 1908, Fondazione Luigi Einaudi, Tutín, aúm, 5912: «Hay dos posibilidades... I) "mi teino no es de este mundo" (Tolstoi), o el sindicalismo pensado basta su úlima consecuencia, que no es nada más que la traducción de la frase "la meta final" no me interesa, el movimiento lo es todo, a lo ético-revolucionario, a lo personol, o 2) la cultura -e.d., la cultura objetiva que se manifiesta en "logtos" técnicos, la afirmación a través de la adaptoción a las condiciones sociologicas de toda "Ia técnica", sea ed(onómi)ca, política o lo que quieta que sea... En el caso ad 2) todas las paiabras (de) "tevolución" son farsa, todo pensaniento de eliminar el "dominio del hombre sobte el hombre" a través de un sistema social, por muy "socialista" que sea, a través de formas de "democracia" por muy refinadas que sear es utopio." Véase además el reconocimiento fundamental de Weber del principio del dominio de los hombres sobre los hombres precisamente dentro de sistemas con legitimación democtática, «Politik als Beruf», Gesammelte politische Schriften, p. 507.

32. Ct. nota 29. 
de líderes», que aún se sirve, en general, del modelo tradicional del parlamentarismo, pero cuyo núcleo es el carisma del gran político que gobierna sobre base personal y plebiscitaria y que puede apelar a las masas por encima de los aparatos burocráticos. Weber consideraba que con ayuda del carisma del gran político era posible volver a activar a un nivel distinto el antiguo ideal del dominio de las gxandes personalidades individuales en el Estado y la sociedad. A la luz de las experiencias posteriores con los sistemas fascistas será imposible aceptar de forma acrítica el concepto de la «democracia plebiscitaria de líderes» que exigía que los aparatos burocráticos se tindieran incondicionalmente al hombre al frente del Estado. No cabe duda de que se trata de un giro elitista de la idea liberal con que Weber pensaba resolver el problema de la creciente falta de liderazgo planteado por el desarrollo de una sociedad altamente capitalista de tipo burocrático. No se puede contestar inequívocamente a la pregunta acerca de la medida en que bajo semejantes condiciones -que el propio Weber calificó en algunas ocasiones de meramente formales- puede ser efectiva la legitimación del dominio de los grandes políticos a través de elecciones en un sistema parlamentario, democrático y constitucional. Sin duda alguna tales construcciones constitucionales que acentúan fuertemente la supremacía de los líderes frente a los ciudadanos no son inmunes a una reinterpretación en sentido autoritario e incluso fascista, como nos lo demuestra también el ejemplo de Robert Michels, que justificó su opción por Mussolini y el fascismo italiano basándose expresamente en la doctrina de Max Weber del político carismático. ${ }^{33}$

Resumiendo, se puede decir que los esfuerzos de Max Weber por Llevar a los límites de lo imaginable los postulados liberales y democráticos clásicos respectivamente terminaron, por un lado, en una serie de dicotomías manifiestas, mientras que, por otro lado, abrieton nuevos caminos para al menos intentar encontrar una solución. Se puede decir que Weber aprovechó integramente en su teoría política las posibilidades del modelo liberal y que agotó todos los medios para desarrollar dicha teoría. Sin embargo, en sus esfuerzos llegó a atravesar el límite del sistema liberal de valores. Propagó soluciones no poco problemáticas a la luz de las experiencias actuales. Cabe decir esto especialmente en relación con su teoría de la "democracia plebiscitaria de líderes», cuyos fundamentos de legitimidad están en contradicción abierta con los postulados democráticos clásicos, también o justamente debido al hecho de que debían garantizar el postulado liberal del dominio de personalidades libres y el manteni-

33. Cf. Wiffried Röhrich, Robert Michels, Vom soziologisch-syundikalistischen zum faschistischen Credo, Berlín 1972, p. 143 g ss. 
miento de una sociedad dinámica de individuos libres, recurriendo al carisma personal del gran político. En la obra política de Max Weber se refleja con mayor claridad que en ninguna otra parte que con el auge de la sociedad industrial de masas había llegado a su término aquella épo $\mathrm{ca}$, mientras que el liberalismo como filosofía política cerrada creía tener a mano soluciones para todos los problemas sociales y políticos $\mathrm{y}$, seguro de sí mismo, podía partir de la base de que el futuro le pertenecería.

El análisis del pensamiento y de la voluntad políticos de Max Weber indica, en un ejemplo de carácter paradigmático, los límites del sistema liberai de valores bajo las condiciones impuestas por las sociedades industrializadas avanzadas. Aquí vemos además la vulnerabilidad especial de los ideales liberales y el gran peligro que corre la voluntad liberal bajo las condiciones políticas del capitalismo tardío. En cierta forma los esfuerzos de Weber por encontrar a través del desarrollo ulterior constante de los postulados liberales clásicos un nuevo fundamento para una política liberal progresista anticipan la crisis del sistema clásico de valores liberales. La sociología política de Max Weber ha demostrado, indicando las razones, que si los postulados liberales se desarrollan con consecuencia extrema, desembocan en su propia anulación. Si algo podemos aptender de ello, será que no es posible deducir de los postulados clásicos del liberalismo unos principios políticos definitivos, válidos para todos los tiempos y para todas las circunstancias sociales. Sin embargo, ello no nos exime de Ia obligación de buscar, según las posibilidades que nos sean dadas en cada caso, un camino para mantener el máximo de libertad. 